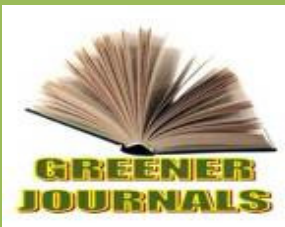

\title{
Perception of Dairy Cattle Owners on Oestrus Synchronization and Mass Artificial Insemination Services in Jimma Zone, South Western Ethiopia
}

\section{*Ahmed Seid, Mohammed Aliy, Nuraddis Ibrahim, Misganu Amanuel}

\author{
Jimma University, College of Agriculture and Veterinary Medicine, Jimma- P.O. Box 307, \\ Ethiopia.
}

Article No.: 072117090

DOI: 10.15580/GJAS.2017.6.072117090

Submitted: $21 / 07 / 2017$

Accepted: 22/07/2017

Published: 29/08/2017

${ }^{\star}$ Corresponding Author

Ahmed Seid

E-mail: seidahmad5@gmail.com

Keywords:

Breeding practice, Heat detection, Hormone treatment
The study was conducted to investigate the perception of dairy cattle owners on oestrus synchronization and mass artificial insemination services in Jimma zone, south western Ethiopia. Two hundred forty nine dairy cattle owners who had used oestrus synchronization and mass artificial insemination services at least once over the last 5 years time were randomly selected and interviewed from three milk shade districts of Jimma zone. All data were analyzed by SAS version 9.2 (2008). Chi-square $\left(x^{2}\right)$ test was carried out to assess the statistical significance among categorical variables. An index was also calculated to provide overall ranking. Majority (73.09 \%) of beneficiaries of oestrus synchronization had low to medium perception about the important management practices like selection of appropriate cows/heifers, asking for quality of the hormone being used (expiration date of the hormone), separation of bulls and hormone treated cows/heifers and time/date of insemination after hormone treatment. Consequently, majority $(67.47 \%)$ of the farmers faced failure of response for hormone treatment at least once. The main reasons for the failure were selection of inappropriate animals $(I=0.40)$, injection of expired or ineffective hormone ( $I=0.37)$ and low dose of hormone (I=0.24). In addition, due to lack of awareness, dairy cattle owners had allowed their bulls to graze together with hormone treated cows/heifers. Moreover, the study also revealed that, $64.66 \%$ of dairy cattle owners in Jimma zone were faced failure of mass Al services. The principal reasons for the failure of mass Al services were heat detection problem $(I=025)$, poor quality semen $(I=0.23)$ and distance of $\mathrm{Al}$ center $(\mathrm{I}=0.22)$. Therefore, in order to enhance the efficiency of the technology and eventually increase the satisfaction of beneficiaries, emphasis should be given on identified problems and concerted effort should be operated from all responsible sectors. 


\section{INTRODUCTION}

The Ethiopia's population, presently estimated to be 91 million, will jump to an estimated 278 million by midcentury (2050). To feed this population, current agricultural production from crops, livestock, fisheries and aquaculture should increase by over $60 \%$ (FAO, 2014). On the other hand, according to CSA (2016), from 57.83 million cattle populations in Ethiopia, only 1.22 percent $(705,526)$ and 0.19 percent $(109,877)$ are hybrid and exotic breeds, respectively. The remaining, 98.59 percent of the total cattle populations are local breeds (CSA, 2016) though the productivity of the native livestock is low due to their genetic makeup, low level of inputs, and traditional husbandry practice besides environmental stress (Sebsibe, 2008; Azage et al., 2010). However, the distribution of native livestock populations across the different agro-ecologies of the country provides various options for tangible and nontangible use of livestock products to the smallholder farmers and pastoral communities (CSA, 2016).

In order to improve the low genetic potential of local cattle in particular, selection of the most promising breeds and cross breeding of these indigenous breeds with highly productive exotic cattle has been considered as a practical solution (Tadesse, 2008). In Ethiopia, artificial insemination had been going on for nearly fifty years. However, it is widely believed that the artificial insemination (Al) service in the country has not been successful to improve reproductive performance of dairy industry (Sinishaw, 2005). Pregnancy rate of dairy cattle to first insemination is $27 \%$ in the conventional Al system (Desalegn et al. 2009). Oromia is one of regional state in Ethiopia having low conception rate which is $34.29 \%$ (Desalegn, 2008). In order to enhance efficiency of $\mathrm{Al}$ service and improve heat detection problem of the dairy farmers, oestrous synchronization and mass artificial insemination (OSMAI) had been adopted as the second applicable reproductive technology and management in areas where dairy development is feasible (Tegegne et al. 1989).

Even though, the conception rate of conventional Al service (27\%) (Desalegn et al. 2009) improved to $39.3 \%$ (Gizaw et al., 2016) for hormone treated dairy cows in Ethiopia, the change was not as expected. A synchronization program to be successful, herd nutrition (cattle must be in good body condition), cycle of estrus (must be normal cycle), and herd health (free from disease and parasites) and weight of the animals must be considered (Lamb, 2010). In addition, if natural service is to be used, bull to cow ratio and age and condition of the bull (the bull need to be 2 years or older, experienced and in good condition) has to be considered (Etherington et al., 1984; Stephen, 2000). Moreover, Azage et al. (2012) reported that awareness creation, proper training, careful animal selection (good body condition score, cows free from diseases and with functional ovaries), good animal handling facility at a convenient location, a well-trained, organized and motivated multi-disciplinary team (livestock science, feeds and nutrition experts, veterinarians, Al technicians, etc.) actively participant community and proper leadership and coordination are key elements for the success of synchronization program. Therefore, this study was designed to investigate the perception of the farmers involved OSMAI as beneficiaries with regard to animal selection, good animal handling facility, management of cows/heifers from hormone treatment to insemination and post insemination, and to identify problems associated with this technology in Jimma zone, western Ethiopia.

\section{MATERIALS AND METHODS}

\section{Description of study area}

The study was carried out in Jimma zone, south west Ethiopia. The capital of this zone is Jimma city which is found $350 \mathrm{~km}$ away from Addis Ababa and lies between $36^{\circ} 50^{\prime} \mathrm{E}$ longitude and $7^{\circ} 40^{\prime} \mathrm{N}$ latitude at an average elevation $1750 \mathrm{~m}$.a.s.I. The climate of the area is characterized by humid tropical with bimodal heavy rainfall which is uniform in amount and distribution, ranging from 1200 to $2800 \mathrm{~mm}$ per year, with short and main seasons occurring from mid February to May and June to September, respectively. In normal years, the rainy season extends from mid February to early October. The ten years mean annual minimum and maximum temperature of the area was $11.3^{\circ} \mathrm{C}$ and $26.2^{\circ} \mathrm{C}$, respectively. The size of the land holdings varies generally from 0.25 to 2.5 ha. Jimma Zone has livestock population of 2,212,962 cattle, 866,561 sheep, 457,311 goats, 96,782 horse, 17,644 mule, 77,767 donkey, $1,951,129$ poultry and 546,722 bee hives (CSA, 2016).

\section{Sampling techniques and sample size determination}

Jimma zone milk shade districts were identified with the help of livestock and fishery resource development office. Three districts were selected purposively from the areas identified as milk shade districts based on number of OSMAI beneficiaries and dairy cattle population. From each district, three rural kebeles practicing synchronization scheme were selected again purposively. From each selected kebeles, households which had participated on OSMAI at least once over the last 5 years time were randomly selected and interviewed.

The representative sample size for households was determined by Yamane's Formula (1967).

$$
\begin{gathered}
n=\frac{N}{1+N(e)^{2}} \\
\text { Where: } n=\text { sample size } \\
N=\text { total number of household } \\
e=\text { Sampling error }
\end{gathered}
$$


Based on the formula, totally 249 households were selected for the study to represent the zone.

\section{Data types and collection methods}

The overall data were collected from primary and secondary data sources. Primary data was gathered through two approaches namely structured questionnaire and group discussions. The questionnaire was translated to local language (Afan Oromo) to make easily understandable and pre-tested before administration and some re-arrangement, reframing and correction was made in accordance with respondent perception. The questionnaires were administered to households by enumerators recruited and trained for the purpose, with close supervision by the researchers.

Based on the questionnaire, perception of the dairy cattle owners about OSMAI program, factors affecting success of synchronization program, and breeding technology and preferences of farmers were collected.

In addition, information was collected from group discussions. A group discussion was organized in villages of three districts with purposely selected youngsters, women, village leaders, developmental agents (DAs), artificial insemination technicians (AITs) and socially respected individuals who are known to have better knowledge on the present and past social and economic status of the area. Group discussions was focused on the history of the breeding practices of dairy cows, utility pattern of the dairy cows and OSMAI services, current status and major constraints of the OSMAI practices and services, major reproductive problems of dairy cows after $\mathrm{Al}$ and their perception about conception rate of Al served dairy cows.

\section{Data management and statistical analysis}

All data gathered during the study period were coded and recorded in Microsoft Excel 97-2003. All data were analyzed by SAS version 9.2 (2008). The data were described and summarized by using descriptive statistics. Chi-square $\left(x^{2}\right)$ test was carried out to assess the statistical significance among categorical variables using district as fixed effect. An index was calculated to provide overall ranking. The ranking being expressed as Index $=$ sum of $(3 X$ reasons for the failure of synchronization ranked first $+2 X$ reasons for the failure of synchronization ranked second $+1 \mathrm{X}$ reasons for the failure of synchronization ranked third) given for each reasons for the failure of synchronization divided by sum of $(3 \mathrm{X}$ reasons for the failure of synchronization ranked first $+2 X$ reasons for the failure of synchronization ranked second $+1 X$ reasons for the failure of synchronization ranked third) for reasons for the failure of synchronization (Kosgey, 2004).

\section{RESULTS AND DISCUSSION}

\section{Perception of beneficiaries on management of cows/heifers in synchronization program}

Majority (73.1 \%) of oestrus synchronization beneficiaries had low to medium perception about the important management practices like selection of appropriate cows/heifers, asking for quality of the hormone being used (expiration date of the hormone), separation of bull and hormone treated cows/heifers, and time/date of insemination after hormone treatment. This could magnify the failure of OSMAI program in the study area. Consequently, majority $(67.47 \%)$ of the farmers in the study area faced failure of response to hormone treatment at least once (Table 1). Similarly, Destalem (2015) reported that majority $(81.2 \%)$ of farmers in central Tigray zone of Tigray region had low to medium perception about oestrus synchronization. Bainesagn (2015) also reported that, $49.1 \%$ of farmers in south Shoa zone of Oromia region had low to medium perception about oestrus synchronization.

The perception of beneficiaries among districts was significantly different $(P<0.01)$. Among dairy cattle owners in all districts, significantly better perception was observed in Seka district cattle owners. As a result, most $(91.1 \%)$ of beneficiaries in Seka district revealed their willingness to pay the cost of hormone if reliable services are given. However, the number of farmers which had faced failure of the technology is relatively high $(72.3 \%)$ in this district. This leads to conclude that most of the causes for the failure were not from the farmer's side. In Mana district only $66.7 \%$ of beneficiaries showed willingness to pay the hormone. This could be due to the influence of previous discouraging results. This variation was significantly $(\mathrm{P}<0.01)$ different among districts.

Moreover, nearly half $(43.0 \%)$ of the beneficiaries had allowed their bulls to graze together with hormone treated cows/heifers. This indicated that the cows/heifers have the possibility to conceive from the local bulls. As the report of AITs during group discussion, after exotic bull semen inseminated to cows/heifers, deliveries of local calves were happened and even farmers had developed lack of trust to inseminators. There was significant difference $(P<0.05)$ across districts for awareness of farmers to keep their cows from bull during heat period.

\section{The major reasons for the failure of hormone treatment}

Majority (67.47\%) of the farmers faced failure of response for hormone treatment at least once (Table 1). The major reasons for failure of hormone treatment were selection of inappropriate animals (poor body condition, pregnant, diseased and fatty cows/heifers), low dose of hormone and injection of expired or inefficient hormone (Table 2). According to the farmers perception, selection of inappropriate cows/heifers was the primary reason for 
the failure of hormone treatment in Seka and Mana districts while in Dedo district injection of expired/inefficient hormone was ranked first. The major reasons for the failure of hormone treatment in this study is slightly consistent with the result of Gizaw et al. (2016) who reported that, the major reasons for the failure of hormone treatment in Oromia, Amahara, Tigray and SNNP region of Ethiopia were feed problem, inappropriate season and low awareness of farmers on the technology (taking hormone injection for insemination and providing sterile and non-cyclic animals for PGF2 $\alpha$ treatment).

Table 1: Perception of dairy cattle owners on oestrus synchronization (OS) and their practice

\begin{tabular}{|c|c|c|c|c|c|c|c|c|}
\hline \multirow[t]{3}{*}{ Perception and Practice } & \multirow{2}{*}{\multicolumn{2}{|c|}{ Seka }} & \multicolumn{2}{|c|}{ District } & & \multicolumn{2}{|c|}{ Overall } \\
\hline & & & \multicolumn{2}{|c|}{ Mana } & \multicolumn{2}{|c|}{ Dedo } & \multirow[b]{2}{*}{$\mathrm{N}$} & \multirow[b]{2}{*}{$\%$} \\
\hline & $\mathrm{N}$ & $\%$ & $\mathrm{~N}$ & $\%$ & $\mathrm{~N}$ & $\%$ & & \\
\hline \multicolumn{9}{|c|}{ What is your perception on OS? } \\
\hline Low & 17 & 21.5 & 34 & 37.8 & 38 & 47.5 & 89 & 35.7 \\
\hline Medium & 24 & 30.4 & 40 & 44.4 & 29 & 36.3 & 93 & 37.3 \\
\hline Good & 36 & 45.6 & 15 & 16.7 & 13 & 16.3 & 64 & 25.7 \\
\hline Very good & 2 & 2.5 & 1 & 1.1 & 0 & 0.0 & 3 & \\
\hline & & & & & & & & 29.8 \\
\hline & & & & & & & & $<.0001$ \\
\hline \multicolumn{9}{|c|}{$\begin{array}{l}\text { Do you allow bulls to go with hormone treated } \\
\text { cows? }\end{array}$} \\
\hline Yes & 26 & 32.9 & 26 & 28.9 & 55 & 68.7 & 107 & 43.0 \\
\hline No & 53 & 67.1 & 64 & 71.1 & 25 & 31.3 & 142 & 57.0 \\
\hline & & & & & & & & 32.24 \\
\hline & & & & & & & & $<.0001$ \\
\hline \multicolumn{9}{|c|}{$\begin{array}{l}\text { Have you faced failure of response to the } \\
\text { hormone treatment? }\end{array}$} \\
\hline Yes & 57 & 72.2 & 60 & 66.7 & 51 & 63.7 & 168 & 67.5 \\
\hline No & 22 & 27.8 & 30 & 33.3 & 29 & 36.3 & 81 & 32.5 \\
\hline & & & & & & & & 3.1 \\
\hline & & & & & & & & 0.5462 \\
\hline \multicolumn{9}{|c|}{$\begin{array}{l}\text { If you are asked to pay cost of hormones, are } \\
\text { you willing to pay? }\end{array}$} \\
\hline No & 7 & 8.9 & 30 & 33.3 & 21 & 26.2 & 58 & 23.3 \\
\hline $\begin{array}{l}\text { Yes } \\
X^{2}\end{array}$ & 72 & 91.1 & 60 & 66.7 & 59 & 73.8 & 191 & 76.7 \\
\hline $\begin{array}{l}x^{2} \\
p\end{array}$ & & & & & & & & $\begin{array}{l}74.68 \\
0.0006\end{array}$ \\
\hline
\end{tabular}

Table 2: The major reasons for the failure of Synchronization program

\begin{tabular}{|c|c|c|c|c|c|c|c|c|c|c|c|c|c|}
\hline \multirow[t]{2}{*}{$\begin{array}{l}\text { Purpose of } \\
\text { keeping }\end{array}$} & \multicolumn{4}{|c|}{ Seka } & \multicolumn{4}{|c|}{ Mana } & \multicolumn{4}{|c|}{ Dedo } & \multirow[t]{2}{*}{$\begin{array}{l}\text { Overall } \\
\text { Index }\end{array}$} \\
\hline & $1^{\text {st }}$ & $2^{\text {nd }}$ & $3^{\text {rd }}$ & Index & $1^{\text {st }}$ & $2^{\text {nd }}$ & $3^{\text {rd }}$ & Index & $1^{\text {st }}$ & $2^{\text {nd }}$ & $3^{\text {rd }}$ & Index & \\
\hline $\begin{array}{l}\text { Selection of } \\
\text { inappropriate } \\
\text { cows/heifers }\end{array}$ & 29 & 21 & 7 & $0.40(1)$ & 46 & 11 & 3 & $0.45(1)$ & 9 & 42 & 0 & $0.36(2)$ & 0.40 \\
\hline $\begin{array}{l}\text { Low dose of } \\
\text { hormone }\end{array}$ & 7 & 14 & 36 & $0.25(3)$ & 5 & 27 & 28 & $0.27(3)$ & 1 & 2 & 48 & $0.18(3)$ & 0.23 \\
\hline $\begin{array}{l}\text { Provision of } \\
\text { expired/ineffici } \\
\text { ent hormone }\end{array}$ & 21 & 22 & 14 & $0.35(2)$ & 9 & 22 & 29 & $0.28(2)$ & 41 & 7 & 3 & $0.46(1)$ & 0.36 \\
\hline
\end{tabular}




\section{Provision of mass artificial insemination services in the study area}

Majority (68.7\%) of farmers in the study area communicated to AITs through phone when they detect sign of heat from their cows/heifers while the other $30.5 \%$ of dairy cattle owners took to Al centers when they look sign of heat on their cows/heifers (Table 3). However, small holder farmers are engaged in various farm activities and are quite difficult for them to detect proper time of heat. The dairy cattle owners could detect the heat time but it might not match with appropriate time of insemination. This leads to the heat period of the cows and heifers passed before the Al service have been given or inappropriate time of insemination that cause failure to conception. Similarly, Bainesagn (2015) reported that, $60.5 \%$ of farmers in south Shoa zone of Oromia region detect heat by their own and took their cows to Al station.

Interestingly, most $(79.1 \%)$ of the farmers in Jimma zone had the awareness and the chance to choose the type of bull breed that the AITs use to inseminate their cows. In addition, around half (55.8\%) of the farmers knew the effect of inbreeding when the AITs use the same bull repeatedly to inseminate their cows. In contrast, Destalem (2015) reported that 100\% of Al user farmer's in central Tigray zone of Tigray region had not idea about selection of semen (bull breed) and $94.4 \%$ of them were not aware about problem of inbreeding.

Table 3: Mass Al Service administration

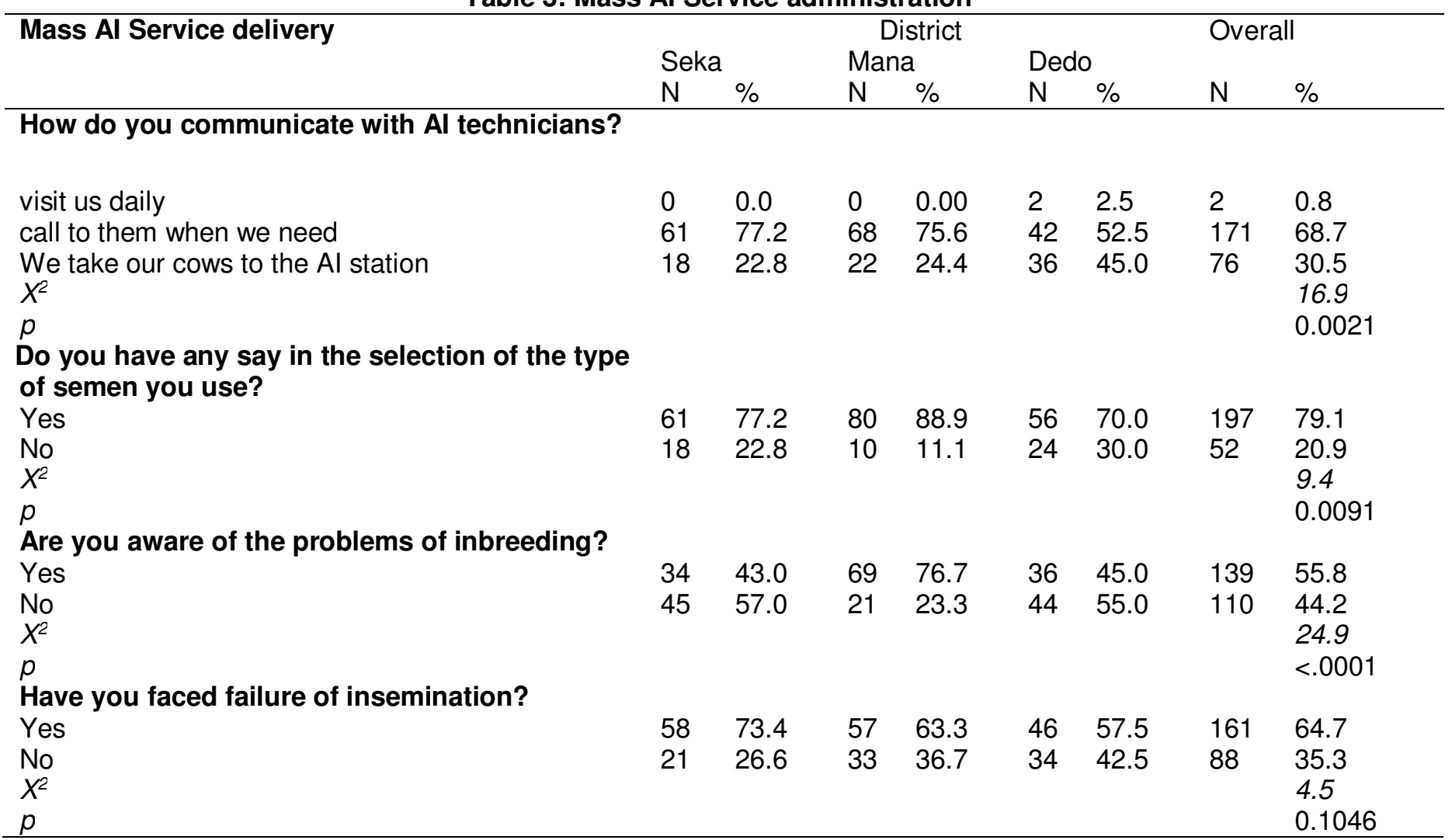

$\mathrm{N}=$ Number of households

\section{The reasons for failure of mass Al services}

Majority $(64.7 \%)$ of the farmers faced failure of mass $\mathrm{Al}$ services at least once (Table 3 ). The major reasons for success of Al services were heat detection problem, $\mathrm{Al}$ technician inefficiency, distance of Al center, shortage of Al technician, disease problem and poor semen quality (Table 4).

The study showed that the primary reason for the failure of Al services in Seka and Mana districts was heat detection problem (discrepancy between time of heat that dairy cattle owners report to AITs and appropriate time of insemination). In Dedo district, beneficiaries of Al services reported that the primary reason for the failure of the service was poor quality semen. In addition, as they reported during group discussion, they had information that sometimes immotile sperm was used for insemination of cows/heifers. Distance of Al center was reported as secondary factor in Mana and Dedo districts while in 
Seka district dairy cattle owners reported that both disease and poor semen quality were secondary factors for resulting inefficient Al services (low conception rate). The major reasons for the failure of mass Al services in this study is in line with the result of Gizaw et al. (2016) who reported that, the major reasons for the failure of $\mathrm{Al}$ services in Oromia, Amahara, Tigray and SNNP region of Ethiopia were, failure to detect heat, poor semen quality/problem in semen handling and low performance of the inseminator.

Table 4: Reasons for the failure of Al service

\begin{tabular}{|c|c|c|c|c|c|c|c|c|c|c|c|c|c|}
\hline \multirow{3}{*}{$\begin{array}{l}\text { Reasons for } \\
\text { the failure of } \\
\mathrm{Al}\end{array}$} & \multicolumn{12}{|c|}{ District } & \multirow{3}{*}{$\begin{array}{l}\text { Overall } \\
\text { Index }\end{array}$} \\
\hline & \multicolumn{4}{|c|}{ Seka } & \multicolumn{4}{|c|}{ Mana } & \multicolumn{4}{|c|}{ Dedo } & \\
\hline & $1^{\mathrm{st}}$ & $2^{\text {nd }}$ & $3^{\text {rd }}$ & Index & $1^{\mathrm{st}}$ & $2^{\text {nd }}$ & $3^{\text {rd }}$ & Index & $1^{\text {st }}$ & $2^{\text {nd }}$ & $3^{\text {rd }}$ & Index & \\
\hline $\begin{array}{l}\text { Heat } \\
\text { detection } \\
\text { problem }\end{array}$ & 13 & 27 & 11 & $0.30(1)$ & 35 & 9 & 4 & $0.37(1)$ & 1 & 6 & 4 & $0.07(5)$ & $0.25(1)$ \\
\hline $\begin{array}{l}\text { Al technician } \\
\text { inefficiency }\end{array}$ & 1 & 0 & 5 & $0.02(6)$ & 3 & 4 & 10 & $0.08(5)$ & 2 & 0 & 0 & $0.02(6)$ & $0.04(6)$ \\
\hline $\begin{array}{l}\text { Distance of } \\
\text { Al center }\end{array}$ & 2 & 8 & 18 & $0.12(5)$ & 14 & 22 & 8 & $0.28(2)$ & 16 & 10 & 3 & $0.26(2)$ & $0.22(3)$ \\
\hline $\begin{array}{l}\text { Shortage of } \\
\text { Al technician }\end{array}$ & 7 & 11 & 13 & $0.16(4)$ & 1 & 10 & 15 & $0.11(3)$ & 0 & 3 & 29 & $0.13(3)$ & $0.13(5)$ \\
\hline $\begin{array}{l}\text { Disease } \\
\text { problem }\end{array}$ & 20 & 3 & 4 & $0.20(2)$ & 2 & 7 & 13 & $0.10(4)$ & 1 & 12 & 8 & $0.13(3)$ & $0.14(4)$ \\
\hline $\begin{array}{l}\text { Semen } \\
\text { quality }\end{array}$ & 15 & 9 & 7 & $0.20(2)$ & 2 & 5 & 7 & $0.07(6)$ & 26 & 15 & 2 & $0.40(1)$ & $0.23(2)$ \\
\hline
\end{tabular}

\section{Breeding practice preferences of dairy cattle owners}

The major breeding practice of dairy cattle owners in Jimma zone were natural mating, Al with naturally cycling cows/heifers (Al without oestrus synchronization) and OSMAI services. Nearly half $(41.4 \%)$ of dairy cattle owners in Jimma zone preferred OSMAl services for their dairy cattle breeding while the other $33.7 \%$ of dairy cattle owners preferred Al without oestrus synchronization (figure 1). In contrary, Destalem (2015) reported that $15.0 \%$ of dairy cattle owners in central Tigray zone of Ethiopia preferred OSMAI services. Moreover, Bainesagn (2015) reported that, only 3.3\% of farmers in south Shoa zone of Oromia region practiced OSMAI services for breeding their dairy cattle. The difficulty of diagnosing early pregnancy through rectal palpation made OSMAI low preferable than conventional $\mathrm{Al}$ and natural mating since administration of hormone to pregnant cows induces abortion (Gizaw et al., 2016). 


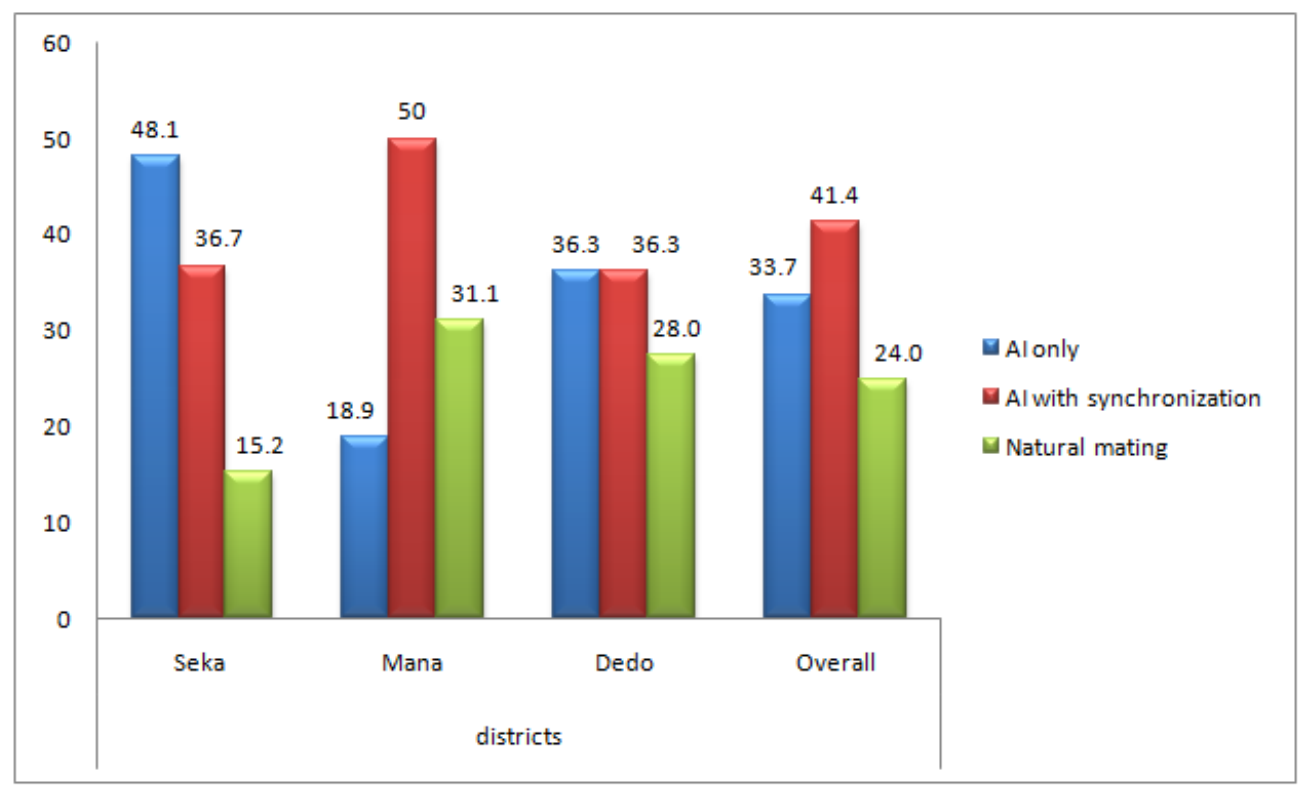

Figure 1: Breeding practice preferences of farmers in the study area

\section{CONCLUSION}

The study revealed that dairy cattle owners in Jimma zone perceived that the main reasons for failure of hormone treatment of cows/heifers were selection of inappropriate animals, low dose of hormone and injection of expired or inefficient hormone. For enhancing the efficiency of the synchronization program all investigated reasons should be strictly considered by respective expertise. In addition, dairy cattle owners had been allowed their bulls to graze together with hormone treated and naturally heated cows/heifers. This indicated that the farmers lack awareness of the cows/heifers to be mated by local bulls and ultimately delivery of local calves which leads to argument between service providers and the farmers. Therefore, intensive training like separation of bulls and cows during hormone treatment and time of insemination should be given for the farmers. Moreover, the study also showed that the primary reasons for the failure of mass Al service in Jimma zone were heat detection problem (discrepancy between time of heat that dairy cattle owners report to AITs and appropriate time of insemination), poor quality semen, distance of Al center, shortage of Al technician and disease. Therefore, the AITs have to round and check the cows/heifers after treated by hormone rather expecting call from farmers, Al centers should be constructed at kebele levels to decrease distance from the farmer's premises and Al centers, training of more AITs, semen quality test and disease diagnosis should be performed before the hormone treatment and insemination of cows is operated.

\section{ACKNOWLEDGEMENTS}

The author greatly acknowledges Jimma University for financial support. Special thanks to my beloved wife Sihen Getachew for her numerous supports in all stages of this work.

\section{STATEMENT OF INTEREST}

The authors declare that there is no conflict of interest involved in this study.

\section{REFERENCES}

Azage Tegegne, Awet Estifanos, Asrat Tera and Dirk Hoekstra (2012). Technological Options and Approaches to Improve Smallholder Access to Desirable Animal Genetic Material for Dairy Development: IPMS (Improving Productivity and Market Success) Experience with Hormonal Oestrus Synchronization and Mass Insemination in Ethiopia. "Resilience of agricultural systems against crises" Göttingen

AzageTegegne, Berhanu Gebremedhin and Hoekstra D (2010). Livestock Input Supply and Service Provision in Ethiopia: Challenges and Opportunities for Market Oriented Development. IPMS (Improving Productivity and Market Success) of Ethiopian Farmers Project Working Paper 20. ILRI (International Livestock Research Institute), Nairobi, Kenya.

Bainesagn Worku (2015). Assessment of Breeding Practices and Evaluation of Estrus Synchronization and Mass Insemination Technique in Dairy Cattle in West Shoa Zone. MSc thesis, Haramaya University, Haramaya, Ethiopia. 
Desalegn G, Medhin, Bekana M, Tegegne A, Blihu B (2009). Status of Artificial Insemination Service in Ethiopia. A paper presented at the 17th Annual Conference of the Ethiopian Society of Animal Production (ESAP), held at the Head Quarters of the Ethiopian Institute of Agricultural Research (EIAR), Addis Ababa, Ethiopia, pp. 87-104.

Desalegn Gebremedhin (2008). Assessment of problems/constraints associated with artificial insemination service in Ethiopia.MSc thesis, Addis Ababa University, Ethiopia

Destalem G/Michael (2015). Breeding Practice and Estrus Synchronization Evaluation of Dairy Cattle in Central Zone of Tigray, Northern Ethiopia. MSc thesis, Jimma University, Ethiopia.

Central Statistical Agency (CSA) (2016). Federal Democratic Republic of Ethiopia, Agricultural Sample Survey, Volume II, Report On Livestock And Livestock Characteristics (Private Peasant Holdings). Statistical bulletin, 583, June 2016, Addis Ababa, Ethiopia.

Etherington ,W G, Bosu, W T, Mart, S, Win, Cote, J F, Doig, P A, and Leslie, KE (1984). Reproductive performance in dairy cows following postpartum treatment with gonadotrophin releasing hormone and/or prostaglandin: a field trial. Canadian Journal of Comparative Medicine; Canadian Veterinary Medical Association.

Food and Agriculture Organization (FAO) (2014). The State of World Fisheries and Aquaculture. FAO Fisheries and Aquaculture Department, Food and Agriculture Organization of the United Nations Rome

Gizaw, S, Tesfaye, Y, Mekuriaw, Z, Tadesse, M, Hoekstra, D, Gebremedhin, B and Tegegne, A (2016). Oestrus Synchronization for Accelerated Delivery of Improved Dairy Genetics In Ethiopia: Results From Action Research And Development Interventions. LIVES Working Paper 12. Nairobi,
Kenya: International Livestock Research Institute (ILRI).

Kosegey I S (2004). Breeding objectives and breeding strategies for small ruminants in the Tropics. Ph.D. Thesis, Wageningen University, The Netherlands.

Lamb G. Cliff (2010). Estrus Synchronization protocols for cows. North Florida Research and Education Center, Marianna, Florida. Proceedings, Applied Reproductive Strategies in Beef Cattle January 28 29, 2010; San Antonio, TX.

Statistical Analysis System (SAS) (2008). Statistical Analysis System for windows, Release 9.2 SAS Institute, Inc., Cary, NC, USA.

Sebsibe A (2008). Sheep and Goat Meat Characteristics and Quality. In Yami A, Merkel RC(eds), Sheep and goat production handbook for Ethiopia. Ethiopian Sheep and Goat Productivity Improvement Program (ESGPIP), 297-324.

Sinishaw W (2005). Study on Semen Quality and Field Efficiency of Al Bulls Kept at The National Artificial Insemination Center. MSc thesis, Addis Ababa University, Faculty of veterinary Medicine, Debre Zeit. Ethiopia. 13-17.

Stephen B. Blezinger, (2000). Estrous synchronization a valuable tool in management of cows and heifers. Cattle Today, Inc.

Tadesse, B (2008). Calf Sex Ratios in Artificially Inseminated and Natural Mated Female Crossbred Dairy Herd. In: Proceedings of the 13 annual Conference of the Ethiopian Society of Animal Production. Addis Ababa, Ethiopia, pp: 227.

Tegegne, A, Warnick, AC, Mukasa Mugerwa, E and Ketema, H (1989). Fertility of Bos Indicus and Bos Indicus $X$ Bos Taurus Crossbred Cattle after Oestrus Synchronization. Theriogenology 31,361-370.

Yamane, Taro (1967). Statistics: An Introductory Analysis, 2nd Edition, New York: Harper and Row. 